\title{
Discussion
}

\section{The Kuhn-loss Thesis and the Case of Phlogiston Theory}

\author{
Rein Vihalemm
}

The Kuhn-loss thesis arguing that scientific revolutions, alongsidegains, involve losses (e. g. those of explanatory power and of problem-solvingability) occupies quite an important position in the Kuhnian theory of the development of science. Notice that in the title of his article on the topic in Science Studies, Veli Verronen (1992) called the Kuhn-loss thesis 'Kuhn's regal argument'. That particular article became a direct impetus to write the present paper. Veli Verronen states that the Kuhn-loss thesis (Kuhn, 1961: 184; 1970a: 107, 148, 169), a model example of which characterises incommensurability between the phlogiston paradigm and Lavoisier's paradigm, is unsatisfactory because it seems to him

very odd to consider phlogiston as a paradigm because that would declare the phlogiston theory as an instance of mature science ... the pair (phlogiston, Lavoisier) which nicely pictures - and may be most nicely of Kuhn's examples - the nature of the loss phenomenon, does not, however, univocally at all lend support to the Kuhn-loss thesis be- cause phlogiston, which may not be a paradigm at all, is at least not a clearcut case of such an entity (Verronen, 1992: 49).

I think that Verronen is right as far as the Kuhn-loss thesis is concerned, i.e. I agree that the loss phenomenon does not characterise paradigm changein mature science but a transition from a pre-scientific natural philosophical period "guided by something much likea paradigm" (Kuhn, 1970a: ix) to a proper paradigm. However, there is still no reason to doubt thescientific nature of thephlogiston theory. As we are going to see below, the question is how to understand the meaning and existence of phlogiston. If we understand phlogiston as a "principle" of pre-scientific chemistry and not as an idealised object introduced into a scientific theory, then indeed “Lavoisier's reform ... ultimately did away with chemical principles, and thus ended by depriving chemistry of some actual and much potential explanatory power" (Kuhn, 1970a: 107), but this does 
not concern the transition from the phlogiston paradigm to Lavoisier's paradigm, which was a paradigm change in scientific chemistry.

\section{The Conception of Kuhn's Paradigm as a Criterion of Science}

The conception of Kuhn's paradigm, although it needs some specification, can beused in order to differentiate between science and non-science since they are incommensurable. It can also beapplied to answer the question in the history of science, when (and in what senseand to what extent) an area of research, for example, chemistry, became a science?

Thescientific world pictureis one but only one component (Kuhn called it the metaphysical part of paradigm or shortly themetaphysical paradigm, which consists of ontological and heuristic models) in the integral paradigm or disciplinary matrix characterising science whose other components, as we know, are symbolic generalisations, shared values and shared examples (Kuhn, 1970a: 174-210; cf. Hoyningen-Huene, 1993: ch. 4). In my treatment I still stick to theterm scientific world picture instead of the metaphysi cal part of paradi gm because, in myopinion, Kuhn is not quiteconsistent, particularly because of the too liberal interpretation of the metaphysical part of paradigm, in defining science through the notion of paradigm (and normal science). I find that, according to Kuhn'sown criteria, before Galileo one cannot speak about an established paradigm with its all four mutually connected components and a normal science functioning on its basis with its puzzle-solving tradition and other features characteristic of mature science.
For example, onecannot speak, as Kuhn does, about Aristotle's mechanics as a science, comparing it with Galileo's or Newton's mechanics. Aristotle's (and mediaeval) mechanics was speculative: it was a natural philosophy, not an empirical science. We can speak about Aristotle's paradigm only as a metaphysical paradigm, showing, like Kuhn does, thatitisincommensurablewith Galileo's or Newton's metaphysical part of paradigm (e.g. Kuhn, 1970a: 118-129). However, it remains unnoticed for Kuhn that Aristotle's mechanics actually was not a paradigm (or disciplinary matrix) characterising a mature scienceaccording to Kuhn's own criteria. The sameshould be said about the Cartesian metaphysical paradigm. This cannot be considered a component of the paradigm characteristic of a mature science either (cf. Verronen, 1992: 49-50).

As we know, Kuhn's paradigm is a notion compatible with the notion of the scientific community, which, like the notion of scientific revolutions, is applicableat numerous levels, from the most global level of natural science in general to very specific achievements in some narrow branch of science (Kuhn, 1970a: 176-178; 1970b: 249-251). It is my opinion that when studying the birth of science historically, then, from the viewpoint of the paradigm conception, we should determine the establishment of the first paradigm that would also be generalisable for the whole science as a paradigm (i.e. not its concrete contents but as a certain type of a manner of cognition, the practice of obtaining knowledge). Without specifying the date of the birth of science and discussing it in the present paper, I rely on the quite generally accepted viewpoint that sciencewas 
born in the form of physics (mechanics) established by Galileo and Newton in the 17th century. I assert that the general cultural precondition for it was that the metaphysical paradigm as thescientific world picture, which Kuhn characterised as a component of the paradigm, could betaken into use as the general interpretation of the world.

The scientific world picture provides a basis for treating the world as a modelled reality and making it natural to treat it so. The world is understood, in the direct sense of the word, through a certain picture which expresses a construction or a mechanism based on a known project (cf. Heidegger, 1977: 115182). Further, scientific vision of the world means viewing phenomena under such conditions where these phenomena behave as idealisations: they can be reproduced and described mathematically since they are subject to the universal quantitative laws of nature. Such conditions are determined experimentally. In this sense, a science itself determines which aspects of the world it investigates and how. For science there exist no phenomenon that could be given for observation independently of the scientific way of treating it. Galileo and Newton began, in principle, to connect mathematics and experiment. They began to study through experiment things that are subject to mathematics, posing the problem so that it would be simultaneously experimental and mathematical, consequently mathematically visible and provable.

In ancient or medieval culturethescientific world picturewas not objectively conceivable. Unfortunately it is impossible to substantiate or analyse this thesis here in detail and I have to confine myself to a few explanatory notes only. Actually, the problem lies in the difference between the ways of thinking in different eras, in the difference between the aims of the natural philosophy of the antiquity and the Middle Ages, and the Galilean-Newtonian science. A. Koyré (seeKoyré, 1995) has analysed theemergence of the Galilean-Newtonian science in connection with the development of metaphysical systems, with changes in the categorial structure of thinking. This caused the replacement of the cosmos as described in Aristotle's philosophy, characteristic of the antiquity and the Middle Ages, by the modern universe, which characterises the scientific world picture The main difference between them is that the former was a world of quality, a world which resembled a big living organism in which the humans also had a certain place and wherethe ideas based on values, perfection, beauty, harmony, meaning, aim, etc. were considered natural. The latter, however, is a quantitative and exact world, subject to mathematics; it resembles a mechanism, a machine. There is no place for humans or human characteristics in it, although it is understandable for the humans because it works according to the experimentally discovered objective laws, according to a rational construction.

\section{Phlogiston Theory as the First Paradigm in Chemistry}

According to my conviction, the birth of scientific chemistry is connected with the establishment of the phlogiston theory that became the first paradigm in chemistry (Vihalemm, 1981; 1975; cf. also Schütt, 1974). Chemistry becamea 
science, in other words, the incommensurability between science and chemistry was overcome in these respects and degrees where the paradigm which had become established in chemistry was similar to the paradigms established in physics. Incommensurability between scientific paradigms and other types of inquiry can be characterised through Kant's "Copernican revolution" (see his famous Prefaceto the $2^{\text {nd }}$ ed. of Critique of PureReason). In scienceproper wecan suppose that objects must conform to our knowledge, not our knowledge to objects. Itisnoteworthy that, whilecharacterising the revolution that led to scientific cognition and applying its coincident basic scheme to different fields of research, Kant also referred, among other things, to Stahl's theory of phlogiston (See Kant, 1929: 20 (B xii-B xiii)).

On the world picture level phlogistic chemistry was included in the general scientific world picture of the time - the Newtonian world picture. In the case of chemistryas a science(like in the case of any proper science), it is impossiblethat the scientific world picture as a component of the paradigm would constitute a specific chemical world picture (cf. Vihalemm, 1982). The scientific world picture is the most universal and the most invariant component of the paradigm, existence of which, as it has been admitted above, is the criterion of whether we have to do with a science or not. It is the most universal component in the sense that, in principle, the scientific world picture is common to science as a paradigm on the global level as well asto a paradigm that characterises a very narrow trend of research in a particular branch of science. This, however, is not to say that all themodels, ideas and prin- ciples of the scientific world picture should be equally essential or find application in the case of each concrete paradigm. On the other hand, it is the most invariant component to the effect that the scientific world picture changes only if there is a change in the global paradigm.

Chemistry deals with qualitative changes of the substance and the production of new substances from other substances. Thescientific world picture, however, does not belong to the world of quality. It was already Boyle's and the Cartesian chemists' goal to show how, on the basis of the general scientific world picture of the time originated from the corpuscular mechanical world view, it was possible to understand the properties, quality and nature of the substance, i.e. everything that enables the scientist to differentiate a particular substance from other substances or to describethe transformation of a substance in a new way avoiding a discussion over the quality or natureas a specific reality, substantial form, mystic capability or power. However, Boyle's and the Cartesian chemists' speculative natural philosophical approach was not able to constructively fulfil thetask of founding scientific chemistry. Another way had to be found in order to get rid of mystic capabilities and powers as well as substantial forms, a way of following the example of mechanics as a science but not treating chemistry mechanistically. And this was the Newtonian way.

The Cartesian mechanical world picture proceeded from the action-by-contact principle. But, differently from this approach, the Newtonian scientific world picture was built on the principle of action at a distance, interpreting the 
links between bodies on the basis of the "mathematical forces" between them. Originally, the notion of force or power seemed to suit scholasticism solely. Still, Newton applied that notion in the meaning of an experimentally determined quantity, but not in the meaning of a substantial form, a certain mystic power or capability. This approach turned out to be mathematically expressed by a functional relation, to be experimentally tested and repeated as a relation between the cause and the effect.

In order to clarify the difference between those two approaches, let us discuss for a moment the issue of chemical affinity, also studied by Newton himself. Boyle and the Cartesians understood chemical affinity mechanistically, claiming that since substances had a corpuscular structure, it was simple to imagine the mutual reaction between them as a manifestation of a better correspondence, worsecorrespondence or non-correspondence between the shape and structure of the particles. It is clear that this way enabled them to avoid mystic powers in interpreting chemical processes, but their concrete imaginations over the suitability of the particles remained arbitrary.

Newton approached the issue differently, strippingasidemechanic imaginations. The fact that chemical substances reacted with each other selectively indicated the principle that the universal gravitational force which was known not to act selectively, did not account for chemical processes. Therefore it was supposed by Newton that chemical impact could be explained by force of attraction acting between small particles of the substance over short distances without any influence over longer distances. It is essential that he did not try to guess the nature of that force, but applied the term solely to express an experimentally determined selective mutual reaction between the substances, thus drawing the attention of chemists to the necessity for experimental research on the manifestations of that force. He made it evident that between substances there was an objective link whose inner nature was still unknown.

Newton's programme proved to suit chemistry; it changed the manner of cognition in chemistry, thus leading to the development of phlogiston theory, the first scientific theory in this realm, and to the compiling of empirical tables of chemical affinity, i.e. to a systematic study of which substances could combine with each other and what was the relative strength of the force holding them together. Unfortunately the formation of scientific chemistry cannot be analysed in detail here. My analysis can be found in earlier publications (see Vihalemm, 1975; 1981).

\section{Transition from the Phlogiston Paradigm to Lavoisier's Paradigm}

The revolution in chemistry - the replacement of phlogiston chemistry by Lavoisier's chemistry - has often been dealt with in the Kuhn-loss thesis and incommensurability discussions. The present analysis attempts to interpret several misconceptions in understanding this revolution, showing that, regardless of changes in the paradigm, Lavoisier's chemistry is more commensurable with phlogiston chemistry than itisusually believed (or as Kuhn thought, too!) (cf. also Perrin, 1988a; 1988b; 1990; 
Gough, 1988; McEvoy, 1988).

Admittedly, a specific feature of the phlogiston theory is its qualitativecharacter, which poses an obstacleto therecognition of its scientificity and correspondence to the Newtonian paradigm. Usually, Lavoisier is undoubtedly considered the founder of modern quantitative scientific chemistry. Indeed, it is indisputable that, on the one hand, Lavoisier introduced the Newtonian quantitative scientific paradigm into chemistry. I would still like to emphasise that, on the other hand, one should recognise the point of view claiming that, by doing this, Lavoisier completed the elaboration of the first scientific, yet, qualitative paradigm of chemistry formed by the phlogiston theory (cf. Gough, 1988). It should be added that Lavoisier performed measuring in units of weight and volume that were nonspecific of chemistry.

With the help of the notion of phlogiston, Georg Ernst Stahl (1659-1734) worded an idea known today as the reversibility of reduction and oxidation reactions. Stahl posed the problem of practical chemistry as a problem of the composition of metals and the residues of their combustion. And besides, he made use of the then applied experimentingtechnique of a qualitative character which meant that no quantitative methods were applied to determinethe composition of a substance. Consequently, it was still impossible to express these issues in mathematical terms. Nevertheless, the problem of practical chemistry was logically also a mathematical one sinceit concerned the loss of a metal in a certain quantity. The mathematical starting point for Stahl was the formally interpreted relation- ship between the part and the whole as the whole equalled the sum of its parts. In order to introduce that scheme into practical chemistry, Stahl obtained qualitative criteria to judge what constituted the wholeand what constituted its parts as well as when the whole disintegrated into parts and when the parts combined into a whole.

Having created his theoretical scheme of phlogistication-dephlogistication, Stahl was able to "synthesise metals", in other words, to construct metals from their component parts. Healso provided a theoretical explanation for the problem of metal loss and indicated a way for retrieving "lost metals" in practice. Phlogiston had to beadded to the metal calx, i.e. the latter had to be processed with a substancerich in phlogiston. In practice, this meant that charcoal, oil, resin or fat was put into themelting-pot. His theory madeit possible to "synthesise" not only metals but also all inflammable mixed bodies (mixta). For instance, sulphur and phosphorus were produced from their acids (really oxides) by that method.

Certainly, the phlogiston theory, especiallyits central notion "phlogiston", also has a connection with the views of traditional chemistry, alchemy, and ancient philosophy. Phlogiston was the inflammable principle. However, "phlogiston" asa "principle" in pre-scientific theories and as a theoretical term in scientific chemistry are radically different. "Phlogiston" indicates, as it is usual for theoretical scientific terms, an idealised object that could not directly be set into correspondence with any existing real object. It was determined by the terms "element", "corpuscle", etc. through the scientific (concretely: the Newtonian 
corpuscular-mechanical) world picture as well as by the idealised scheme of the reversible opposite processes of combustion and reduction. By no means was phlogiston understood to be an object that could be directly observed during the experiment. I agree, for instance, with Alexander Bird that

A straightforward Putnamian theory could not work for the meaning of "phlogiston." But the phenomenon in question, combustion, does exist, and so phlogiston could behypothesised as that thing which explains combustion, as a substance contained in inflammablematerials, and given off by combustion (Bird, 1998: 110).

It meant that to consider the phlogiston theory fantastical because phlogiston could not be separated and bottled was much the same as to consider classical mechanics fantastical because its term "material point" or "particle" could not be displayed either.

A peculiarity of the phlogiston theory, as I have pointed out, lies in its qualitativeness. In other words, the idealisations supporting thetheory have been derived on the basis of the qualitative transformations of substances only. It is clear that as long as the qualitative approach in chemistry was sufficient, the phlogiston theory wholly met the needs of chemistry.

Now let ustakea look at the quantitative approach of Lavoisier that replaced the phlogiston theory. The phlogiston theory and theoxygen theory can indeed be treated as different paradigms in terms of Kuhn. Let us examine in some detail the features characteristic of both the phlogiston theory and the oxygen theory as different paradigms.

As we know already, the world picture (or metaphysical part of a paradigm in Kuhn's terminology) of the phlogiston theory was principally Newtonian (as opposed to the views of Descartes and Boyle), yet, qualitativelikethetraditional treatments of chemistry. As a qualitative theory it was characterised by theexplanation of the properties and the change of the properties of chemical substances in chemical reactions on the basis of elementary composition of substances, comprehended qualitatively since the elements were identified according to the properties whose permanent primary causes they were. The principle can be called the principle of the conservation of matter comprehended qualitatively.

The world picture of the oxygen paradigm (i.e. the metaphysical part of the paradigm by Kuhn) was Newtonian not only in terms of its general principle, but it also essentially proceeded from Newton's ideas of matter as mass that can be qualified by weighing.

While explaining the properties of substances, Lavoisier's paradigm also proceeded from their composition, but in order to determine the composition the quantitative criteria and the principle of the conservation of the quantity of matter served as the consistent bases. In other words, the principle of the conservation of matter was understood quantitatively. This quantitative criterion rendered it possible to clearly differentiate elements from compound substances.

The common and different features of the methodological principles of the phlogiston theory and of the oxygen theory generally arisefrom the common and different features of the world pictures (metaphysical paradigms) of those 
theories. Therefore their difference manifests itself in their attitudetowards the quantitative methods of investigation. However, it has to be stated here and now that it would be wrong to accuse the proponents of the phlogiston paradigm ofignoringquantitativemethods. "Phlogistonists", Cavendish for one, frequently conducted very accurate quantitative investigations. It does not matter whether quantitative investigations were carried out or not and how precisethose measurements were. What matters is whether the starting point of chemical research was either a qualitative or a quantitative scheme.

Owing to the differences in the scientific world picture and themethodological starting points of the above paradigms, "symbolic generalisations" also differed in them. The basic equation of chemical reactions was understood by Lavoisier in the light of the law of the conservation of the weight of the reacting substances. However, "the symbolic generalisations" of the phlogiston theory were derived from the phlogisticationdephlogistication scheme.

Among the concrete examples one could also detect obvious differences that, generally speaking, depended on their relative importance in the quantifying (or measurement) operations with the substances.

Now, if we consider the transition from a paradigm based upon the phlogiston theory to a paradigm based on the oxygen theory, we can, first of all, state that the phlogiston paradigm was based on a qualitative approach whereas Lavoisier based his paradigm on a quantitative approach. Still, I would like to emphasise that the Lavoisier paradigm was formed in the course of a direct transfer of not only the physical ("nonchemical") measurement techniquebut also of physical ("non-chemical") units of measurement to the field of qualitativeresearch in chemistry. Therefore, the Lavoisier quantitative approach in chemistry was, regardless of a paradigm change, a continuation of the earlier qualitative investigations with more accurate and sensitive means.

After all, the Lavoisier paradigm did not produce any quantitative law in chemistry. The weighing of substances, the measuring of the volumes of gases and theapplication of thelaw of theconservation of mass made it possible to merely differentiate between chemical substances and to determinethe nature of the processes (e.g. whether it was a decomposing or combining reaction) even when it was impossible to determineit in another way. Lavoisier had no clear theoretical answer to the question of what a particular chemical substance in fact was and how to measure its amount? The chemical units necessary for determining the amounts of substances could be introduced only with the creation of the atomic-molecular theory founded by John Dalton.

\section{Conclusions}

First of all I would liketo emphasise that Verronen's main argument in his criticism of the Kuhn-loss thesis in this journal (Verronen, 1992) proves to be acceptable. Indeed, Kuhn himself failed to establish the so-called Kuhn-loss thesis. Verronen argued rightly that this thesis presupposes the existence of maturescience and a transition from one successive paradigm to another so that the achieved solutions to some problems get 
lost, while Kuhn's case examples of the loss phenomenon do not characterise paradigm change in mature science but a transition from a pre-scientific natural philosophical period to a normal scienceor, in other words, from a pre-paradigm to a paradigm. Nevertheless Verronen's argument needs following specifications.

Model examples presented by Kuhn were the transition from the Cartesian view to Newton's paradigm and especially the transition from the phlogiston theory to Lavoisier's chemistry. Verronen held that both of them - the Cartesian view and the phlogiston theory as well were not instances of mature science, and for that reason theseexamplescould not support the Kuhn-loss thesis. However, concerning the phlogiston theory, Verronen is right as he takes the phlogiston examplesfor analysisfrom Kuhn's texts i.e. in the presentation and interpretation given by Kuhn. Kuhn's presentation and interpretation of the phlogiston theory and theChemical Revolution, however, prove to be non-acceptable. The phlogiston theory as a scientific theory and paradigm wasunsuccessfully presented and analysed by Kuhn, even from the point of view of his own theory. For that reason Verronen was able to demonstrate that the phlogiston theory was not a scientific paradigm according to Kuhn's own criteria, and therefore the Kuhn-loss phenomenon could not be supported by the case of the Chemical Revolution. By applying Kuhn's theory in a somewhat specified form to the respective studies of the history of chemistry, I show in this paper that the phlogiston theory in fact is a scientific theory and paradigm. But the Chemical Revolution still does not support the Kuhn- loss thesis because in the transition from the real phlogiston paradigm (i.e. interpreting thephlogiston theory as a proper scientific theory belonging to a specified Kuhnian paradigm) to Lavoisier's paradigm, there were simply no real scientific achievements that got lost. It goes without saying that we should, then, keep understanding phlogiston as a "principle" of prescientific chemistry, but as an idealised object introduced into a scientific theory.

I hopel have proved in this paper that the conception of Kuhn's paradigm, although it needs some specification, can beused to discriminatebetween science and non-science since they are incommensurable. The main point in which Kuhn's notion of paradigm needs specification is its component called by him themetaphysical part of paradigm. In my opinion, Kuhn was not quite consistent, particularly because of his too liberal interpretation of the metaphysical part of paradigm, in defining science through thenotion of paradigm (and normal science). Namely, Kuhn occasionally contradicts his own criteria of scientificity, according to which, science was born in the form of physics (mechanics) established by Galileo and Newton. Beforethe Galilean-Newtonian scienceonecannot speak about an established paradigm with its all four mutually connected components and a normal sciencefunctioning on its basis with its puzzle-solving tradition and other features characteristic of mature science. I have specified that the general cultural precondition for scientificity is that the metaphysical paradigm as thescientificworld picture, which Kuhn characterised as a component of the paradigm, could be taken into use as the general and natu- 
ral interpretation of the world. The scientific world pictureis the most universal and the most invariant component of the paradigm.

Phlogiston chemistry and Lavoisier's chemistry are based on the same general Newtonian scientific world picture. They arenotincommensurablelikeprescientific and scientific conceptions. Nevertheless, they can betreated as different paradigms in terms of Kuhn. Admittedly, a specific feature of the phlogiston theory is its qualitative character, and Lavoisier's approach introduced the Newtonian quantitative scientific paradigm into chemistry. It must be stressed, however, that this physically quantitative approach in chemistry was, regardless of a paradigm change, a continuation of the chemical qualitative investigations, formed in the framework of the phlogiston theory, with more accurate and sensitive physical means.

\section{Acknowledgements}

I would like to thank IImar Anvelt and Georg Allik for editing the English language and a referee of this journal for helpful suggestions and criticisms to the earlier version of this paper.

\section{References}

Bird, A.

1998 Philosophy of Science. London: UCL Press.

Gough, J.B.

1988 "Lavoiser and the Fulfillment of the Stahlian Revolution." Pp. 15-33 in A.Donovan (ed.). The Chemical Revolution: Essays in Reinterpretation (Osiris, Second Series, 4).

Heidegger, M.

1977 The Question Concerning Technology and Other Essays. Translated and with an Introduction by William Lovitt. New York: Harper \& Row

Hoyningen-Huene, $P$.

1993 Reconstructing Scientific Revolutions: Thomas S. Kuhn's Philosophy of Science. Chicago \& London: The University of Chicago Press.

Kant, I.

1929 Critique of Pure Reason. Translated by Norman Kemp Smith. London: Macmillan.

Koyré, A.

1995 "The Significance of the Newtonian Synthesis." Pp. 58-72 in I.B.Cohen and R.S.Westfall (eds.) Newton:Texts, Background, Commentaries. New York: Norton.

Kuhn, T.

1961 “TheFunction of Measurement in Modern Physical Science." Isis, 52: 161- 193.

1970aThe Structure of Scientific Revolutions. $2^{\text {nd }}$ ed. Chicago: University Press.

1970b “Reflections on my Critics." Pp. 231278 in I.Lakatos, A.Musgrave (eds.) Criticism and the Growth of Knowledge. Cambridge: University Press.

McEvoy, J. G.

1988 "Continuity and Discontinuity in the Chemical Revolution." Pp. 195-213 in A.Donovan (ed.). The Chemical Revolution: Essays in Reinterpretation (Osiris, Second Series, 4).

Perrin, C. E.

1988a "Research Traditions, Lavoisier, and the Chemical Revolution." Pp. 53-81 in A. Donovan (ed.). The Chemical Revolution: Essays in Reinterpretation (Osiris, Second Series, 4).

1988b "The Chemical Revolution: Shifts in Guiding Assumptions." Pp. 105-124 in Donovan et al. (eds). Scrutinizing Science: Empirical Studies of Scientific Change. Dordrecht: Kluwer.

1990 "Chemistry as Peer of Physics: A Response to Donovan and Melhado on Lavoisier." Isis, 81: 259-270.

Schütt, H.-W.

1974 “Was hat Chemiezu einer Naturwissenschaft gemacht? Eine wissenschaftstheoretishe Betrachtung zur Phlogistonlehre von Stahl und zur Oxidationslehre von Lavoisier." Die Chemieunterricht, 5, 2: 56-70. 
Verronen, V.

1992 "A weakness in Kuhn's regal argument." Science Studies, 5, 1: 47-51.

Vihalemm, R.

1975 "Concept of Scientificity and Formation of Scientific Chemistry." Acta et Commentationes Universitatis Tartuensis, 361: Proceedings in Philosophy XVIII: 20-42 [in Russian].

1981 The History of Formation of a Science: On the Development of Chemistry. Tallinn: Valgus [in Estonian].

1982 "Is a Chemical Picture of the World Possible? (On the Particular Scientific Pictures of the World.)" Filosofskie nauki, 1: 148-151 [in Russian].

Rein Vihalemm

Department of Philosophy

University of Tartu

Tartu, Estonia 